\title{
A new technique for identification of flow units of shaly sandstone reservoirs
}

\author{
Shedid A. Shedid ${ }^{1}$
}

Received: 19 September 2016/ Accepted: 13 April 2017/Published online: 28 April 2017

(C) The Author(s) 2017. This article is an open access publication

\begin{abstract}
The available techniques for identification of flow units of shaly sandstone reservoirs are based on different concepts, do not provide satisfactory results, and usually show discrepancy. This research is devoted to evaluating current techniques and developing a new concept capable to identify flow units constituting shaly sandstone reservoirs. A new mathematical model has been developed and validated to identify flow units in shaly sandstone reservoirs. The newly developed concept is called shale number ( $\mathrm{SN}$ ) and combines rock properties, fluid properties, petrophysical properties, and hydraulic flow conditions of shaly reservoir rocks. Fifteen actual, reserved, and fracture-free reservoir samples of shaly sandstone reservoir are used to develop SEM images and measure required rock properties of porosity, permeability, and oil/brine relative permeability. The developed data using SEM images and lab experiments are used to characterize the rocks, test feasibility of permeability-porosity crossplot and flow zone index (FZI) techniques, and validate the newly developed mathematical model. The results revealed that the SEM images are capable to identify the clay types as detrital clays and hairy illites plus clay distribution as filling micropores and coating grains of shaly sandstone formations. The results have proven that techniques of porosity-permeability crossplot and FZI have severe scattering degree of data and poor capability for identification of flow units of shaly sandstone reservoirs. The developed model of SN has been validated and showed superior accuracy in application. A plot of $\mathrm{SN}$ versus reservoir quality $(\sqrt{K / \varphi})$ provided unique straight lines
\end{abstract}

Shedid A. Shedid

s.shedid@aucegypt.edu

American University in Cairo (AUC), Cairo 11835, Egypt passing through the origin and capable to delineate flow units of shaly sandstone reservoirs. The newly developed shale number overcomes several drawbacks of previous and current techniques used for identification of flow units. Therefore, the application of the new technique provides improved reservoir description of shaly sandstone reservoirs, which secures better development planning.

Keywords Shaly reservoirs - Reservoir characterization · Flow units $\cdot$ Reservoir description

\section{List of symbols}

$A, B, C \quad$ Empirical constants

$A_{\mathrm{o}}, A_{1} \quad$ Empirical constants for fabric technique

$B_{\mathrm{o}}, B_{1} \quad$ Empirical constants for fabric technique

$D_{\mathrm{p}} \quad$ Pore diameter, inch

$K_{\text {sh }}, K$ Shaly sandstone and clean permeability, respectively, md

$\mathrm{GV} \quad$ Grain volume, $\mathrm{cm}^{3}$

$\mathrm{J}\left(S_{\mathrm{w}}\right) \quad \mathrm{J}$-function, dimensionless

$K \quad$ Rock permeability, md

$K_{\mathrm{ro}}, K_{\mathrm{rw}} \quad$ End points of oil and water relative permeability curves

IFT Interfacial tension, $\mathrm{N} / \mathrm{cm}$

PV Pore volume, cubic centimeter

$R_{\mathrm{w}} \quad$ Water resistivity, ohm-m

$R_{\mathrm{t}-\text { irr }} \quad$ True formation resistivity at irreducible water condition, ohm-m

RQI Reservoir quality index, micron

FZI Flow zone index

SEM Scanning electron microscope

SN Shale number, dimensionless

FU Flow unit

$R_{\mathrm{x}} \quad$ Pore throat radius at x saturation (\%) of a nonwetting phase

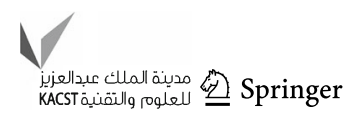


$V_{\text {sh }} \quad$ Shale content, fraction

RQI Reservoir Quality Index, micron $(\mu \mathrm{m})$

$S_{\mathrm{w}} \quad$ Water saturation, fraction PV

$V_{\mathrm{o}} \cdot V_{\mathrm{w}} \quad$ Velocity of oil and water, respectively, $\mathrm{m} / \mathrm{sec}$

\section{Symbols}

X Rock-fabric number

$\phi_{\text {sh }} \quad$ Shaly sandstone porosity, fraction

$\Phi \mathrm{z} \quad$ Pore volume-to-grain volume ratio

Ho Viscosity, centipoises

$\rho_{o} \quad$ Oil density, $\mathrm{gm} / \mathrm{cm}^{3}$

$\sigma_{\mathrm{O}-\mathrm{W}}$ Oil-water interfacial tension, dyne/cm

\section{Super/subscripts}

EP End point of relative permeability curve

irr Irreducible

$\mathrm{m}_{\mathrm{sh}} \quad$ Cementation exponent for shaly formation

o Oil

sh Shale

w Water

wir Water irreducible

\section{Introduction and literature review}

Better understanding of reservoir characterization represents key element and critical component for successful field development planning of shaly reservoirs. Accurate reservoir characterization is a prerequisite for efficient and better management of heterogeneous shaly reservoirs. It is important to have a comprehensive understanding of heterogeneity and structural complexity of shaly reservoir under development.

Reservoir characterization is defined as a combined technology using geostatistics, geophysics, petrophysics, geology, and reservoir engineering data to provide detailed description of the reservoir for better reservoir development planning to attain the highest recovery at minimum cost and reduce to a minimum uncertainty in production forecasts (Haldorsen and Damsleth 1993; Phillips 1996). Practical reservoir characterization for compartmentalized heterogeneous reservoirs still represents a real challenge for shaly formations and very difficult endeavor in the oil industry.

The method of hydraulic flow unit has been widely used for classification of rock types in pore scale according to flow properties based on geological parameters and physics of flow. These flow units represent similar compartments of the whole reservoir which have similar geological and petrophysical properties that affect fluid flow and are different from other compartments of the reservoir (Shedid et al. 1998a, b, c; Shedid 2001).
Geologists defined the flow units based on similar depositional and diagenetic environments, using core description and core analysis in cored wells and described them as geological flow units or lithofacies (Ebanks 1987). Geoscientists and geostatisticians (Lee and Datta-Gupta 1999; Duval 2002) introduced and applied the concepts of lithofacies, seismic facies, and electrofacies, but none of these techniques has provided satisfactory results in explanation of complex nature of shales and hydraulics of the reservoirs. Electrofacies analysis is a system for identifying rock types with similar properties out from wireline logs and then delineates the reservoir rocks from the nonreservoir rocks. The technique uses the clustering permeability (K)-mean algorithm which is based on log responses to identify electrofacies.

Petrophysicists characterize flow units based on similar responses of $\log$ measurements and describe them as electrofacies. Reservoir engineers characterize flow units based on similar pore size distribution and capillary pressure data with consideration of reservoir conditions (Tiab and Donaldson 2004).

For reservoir engineering applications, reservoir characterization is defined as a reservoir modeling technique that considers rock and fluid properties and predicts the fluid behavior in the reservoir using all available sources of reservoir data including relative permeability (Shedid and Almehaideb 2003).

Shale is type of clastic sedimentary rock comprised dominantly of clay minerals and other clay size fragments contains some silt-sized grains of quartz and feldspar, but other minerals may contain organic frags of source rock. Shale is a fissile rock that splits along bedding planes but claystone has a massive appearance and not fissile. Shales can cause complications for the petrophysicist because they are generally conductive and may therefore mask the highresistance characteristic of hydrocarbons (Toby 2005). In addition, special equipment is required for evaluation shaly rocks due to a very heterogeneous nature and extreme variation of shale properties.

Nowadays, there is a challenging endeavor of defining the reservoir rock regions that have similar petrophysical and geological properties and also consistently different from surrounding zones for better characterization, modeling and simulation of shaly reservoirs. Modeling reservoir zonation has attracted considerable interests for clean (non-shaly) reservoirs. In the meantime, shaly reservoirs have a little attention because of complexity of shale types and various distribution modes. A brief review of the common flow unit delineation techniques is presented below. 


\section{Reservoir characterization techniques}

Geologists, geostatisticians, and reservoir engineers proposed several techniques for reservoir characterization but many of them are in an empirical fashion and mainly not developed for shaly formations. Popular techniques for flow unit zonation of clean and shaly reservoirs are briefly summarized below;

\section{Permeability-porosity crossplot technique}

Permeability and porosity of reservoir rock are considered as the most important parameters for estimation of reservoir reserve and production (Ahmed 2001; Tiab and Donaldson 2004). Several studies have been presented to provide permeability-porosity relationships and crossplots. Winland (1972) and Pittman (1992) developed the correlation below;

$\log \left(K_{\text {air }}\right)=\log (A)+B \log (\varnothing)+C \log \left(R_{\mathrm{x}}\right)$

where $K_{\text {air }}$ is air permeability (md) and $\varnothing$ is rock porosity (fraction). $R_{\mathrm{X}}$ is the pore-throat radius at x saturation (\%) of a non-wetting phase and $A, B$, and $C$ are different empirical constants for sandstone and carbonate reservoirs. Theoretically, all points of the same $R_{\mathrm{x}}$ should have the same flow unit and lie on a straight line on a $\log -\log$ plot of permeability and porosity.

Coates and Dumanoir (1973) developed the following equation for permeability of shaly sand formation;

$\sqrt{K_{\mathrm{sh}}}=\frac{300 \varphi^{2 \mathrm{~W}}}{\mathrm{~W}^{4} \frac{R_{\mathrm{w}}}{\left(R_{t-\mathrm{ir}}\right)_{\mathrm{adj}}}}$

where $R_{\mathrm{w}}$ is water resistivity (ohm-m) and $R_{\mathrm{t}-\text { irr }}$ is true formation resistivity at irreducible water condition (ohm$\mathrm{m}$ ) and coefficient $\mathrm{W}$ is approximated $\sim 2.0$. Equation 2 is restricted in application to the existence of irreducible water condition, which often disappears after primary phase.

Revil and Cathles (1999) developed the following equation for predicting permeability of shaly reservoirs;

$K_{\mathrm{sh}}=K_{\mathrm{o}}\left(\frac{\varphi_{\mathrm{sh}}}{\varphi_{\mathrm{o}}}\right)^{3 m-\mathrm{sh}}$

where $K_{\mathrm{sh}}$ and $K_{\mathrm{o}}$ are shaly and clean permeability (md), respectively. $\varnothing_{\text {sh }}$ and $\varnothing_{\mathrm{o}}$ are shaly and clean porosity (fraction), respectively. The cementation exponent is $m_{\text {sh }}$ for shaly formation. The cementation exponent $\left(m_{\mathrm{sh}}\right)$ is not only a positive function of the shale content but can reach values much higher than 2.0.

Jennings and Lucia (2001) developed the rock-fabric technique, which is based on the following correlation for carbonates; $\log K=0.4342 A_{\mathrm{o}}-A_{1} \log (\chi)$

$$
+\left\{B_{\mathrm{o}}-2.303 B_{1} \log (\chi)\right\} \log (\varnothing)
$$

where $A_{\mathrm{o}}, A_{1}, B_{\mathrm{o}}$, and $B_{1}$ are empirical constants and parameter $X$ is the rock-fabric characteristic number. The rock-fabric number showed the correlation between porosity $(\varnothing)$, water saturation, and capillary pressure derived from mercury injection.

Apparently, there is no theoretical basis to support the traditional crossplot of the logarithm of permeability versus porosity. Permeability is plotted as a log function only because it appears to be log-normally distributed.

\section{The J-function technique}

The J-function by Leverette (1941) has been widely used in the oil industry to characterize non-shaly reservoir media. The J-function combines several reservoir parameters in a dimensionless function, called J-function (Ahmed 2001; Tiab and Donaldson 2004). The J-function is given by Eq. 5 below:

$J\left(S_{W}\right)=\frac{P_{\mathrm{C}}}{\sigma_{\mathrm{o}-\mathrm{w}} \operatorname{Cos} \theta} \sqrt{\frac{K}{\varphi}}$

where Pc is the capillary pressure (psig), $K$ is rock permeability (md), $\varnothing$ is effective rock porosity (fraction), $\sigma_{\mathrm{o}-\mathrm{w}}$ is oil-water interfacial tension (dyne/cm), and $\Theta$ is contact angle reflecting rock wettability.

The $\mathrm{J}$-function is popular in averaging capillary pressure data for specific rock type from a given reservoir and can sometimes be extended to different reservoirs having the same lithology. It is important to use extreme caution in assuming that this can be done. The reasons for the Leverette J-function inaccuracy may be attributed to the existence of capillary pressure, which is restricted to only the transition zones and lower values of applied capillary pressure measurements. In addition, the J-function inability to identify the flow units is due to the functional form of the J-function combining porosity, permeability, capillary pressure, and contact angle does not allow for reservoir flow unit characterization.

Shedid (2001) developed another J-function suitable for shaly reservoirs. It is based on using in situ conventional well logging data, which is more representative to wettability condition and also have less error chance than routine core measurements of porosity and permeability.

\section{Carman-Kozeny-based techniques}

Amaefule et al. (1993) used the generalized form of the Carmen-Kozeny relationship to develop the Reservoir Quality Index (RQI) equation, which is given below; 
$\mathrm{RQI}=0.0314 \sqrt{\frac{k}{\varphi_{\mathrm{e}}}}$

where RQI is Reservoir Quality Index (micron), $k$ is clean rock permeability (md) and $\varphi_{\mathrm{e}}$ is effective porosity (fraction).

The Reservoir Quality Index (RQI) represents an approximation of average hydraulic radius and correlates porosity and permeability for flow units' identification of non-shaly reservoirs. Values of pore-grain ratio $\left(\varphi_{\mathrm{z}}\right)$ and flow zone index (FZI) can be calculated by the following equations;

$\varphi_{\mathrm{z}}=\frac{\varphi_{\mathrm{e}}}{1-\varphi_{\mathrm{e}}}$

$\mathrm{FZI}=\mathrm{RQI} /\left(\varphi_{\mathrm{z}}\right)$

Taking logarithm from both sides of Eq. 8, the following equation was derived:

$\log (\mathrm{RQI})=\log \left(\varphi_{\mathrm{z}}\right)+\log (\mathrm{FZI})$

Equation 9 presents a straight line with slope of unity in a $\log -\log$ plot of RQI vs, $\varphi z$. The points which lines meet $\varphi \mathrm{Z}=1$ is the average FZI for respective hydraulic unit. Average FZI is useful for estimating permeability of the wells which have no cores. Intersection of this straight line in $\varphi_{\mathrm{z}}$ equal to one is the flow zone index (FZI). Samples which are on a straight line happen to have similar properties and so contribute to make a flow unit. Straight lines with slope of unity are firstly expected for non-shale containing sandstone formation.

The same concept of RQI, given by Eq. 6, was extended for identifying hydraulic flow units in shaly sand reservoirs using different water saturation models of laminated, dispersed, and cation exchange capacity (CEC) shaly sands (Jongkittinarukorn and Tiab 1997; Shedid Elgaghah et al. 2001a, b). These models suffer from absence of irreducible water condition for depleted reservoirs and also they still rely on Carmen-Kozeny idealized porous media represented by a bundle of capillary tubes.

The main objectives of this study are to develop a new model capable to overcome drawbacks of current methods based on Carmen-Kozeny model and identify hydraulic flow units in shaly sandstone reservoirs. The newly developed model combines rock properties, fluid properties, rock-fluid properties and also dynamic conditions of fluid flowing into the shaly sandstone porous medium.

\section{Experimental setup, procedures and results}

Field under consideration is an onshore oil reservoir, located in the Middle East and producing from a shaly sandstone formation. The reservoir is a saturated oil reservoir and geologically has an anticline structure. The provided data by the operating company has shown that zone $\mathrm{B}$ of the field contains two geologically different rock lithofacies of $\mathrm{C}$ and $\mathrm{K}$.

The laboratory tests were performed to provide routine data of porosity, absolute permeability, saturation, and special data of brine/oil relative permeability. A suit of fifteen actual core samples free of fractures was extracted from three wells A, B and C of an actual shaly sandstone oil reservoir. These cores were coated with aluminum foil and sealed in plastic bags for preservation purpose. The samples were brought to the laboratory and actual formation brine (130,700 mg/liter salinity) of viscosity of $1.01 \mathrm{cp}$ was used as a bit lubricant to cut the cores parallel to the bedding plan with dimensions of 2 inch diameter and 3 inch length. The dean shark was used to clean the cores in cold solvent (chloroform \& methanol) extraction soxhlets.

The samples were placed in a drying humidity oven at $75{ }^{\circ} \mathrm{C}$ until constant weights were achieved. The plug samples were left to cool to room temperature at $32{ }^{\circ} \mathrm{C}$ in a sealed container containing silica gel before start of testing. Chemical and microscopic checks were undertaken to ensure removal of all contaminants prior to testing and core analysis. During this step, the volume of actual brine required to completely saturate the core was measured and used to calculate pore volume of core samples. Then, effective rock porosity was calculated volumetrically.

The core flood apparatus, shown in Fig. 1, used for measurement of absolute and brine/oil relative permeability consists of a 260-ml-capacity syringe pump and a controller system (Model ISCO-260D) and a stainless steel core holder placed in a variable temperature oven. Backpressure regulator and digital pressure and temperature transducers were connected to both ends of the core inside the core holder for recording the data. Absolute permeability and porosity were measured for all samples under a confining pressure of 800 psig.

It is important for shaly rocks to consider only absolute and relative permeability measurements to be carried out with saline water. Moore et al. (1982) showed that fresh water destabilizes clay minerals, and the permeabilities measured with fresh water are greatly underestimated.

Some laboratory modifications were made for more accuracy of shaly sandstone samples such as; reconfiguration of brine circulation for better temperature stability, improved digitizing resolution using better data logger, and good temperature control. The results of permeability and porosity measured are listed in Table 1 .

For relative permeability measurement, the samples were subjected to actual reservoir brine and fully saturated samples were placed in the core holder and a refined mineral oil having similar reservoir oil-water viscosity ratio of 9.4, was injected into the top of the core. The actual brine effluent was measured and the test was terminated 
Fig. 1 Experimental core flooding system

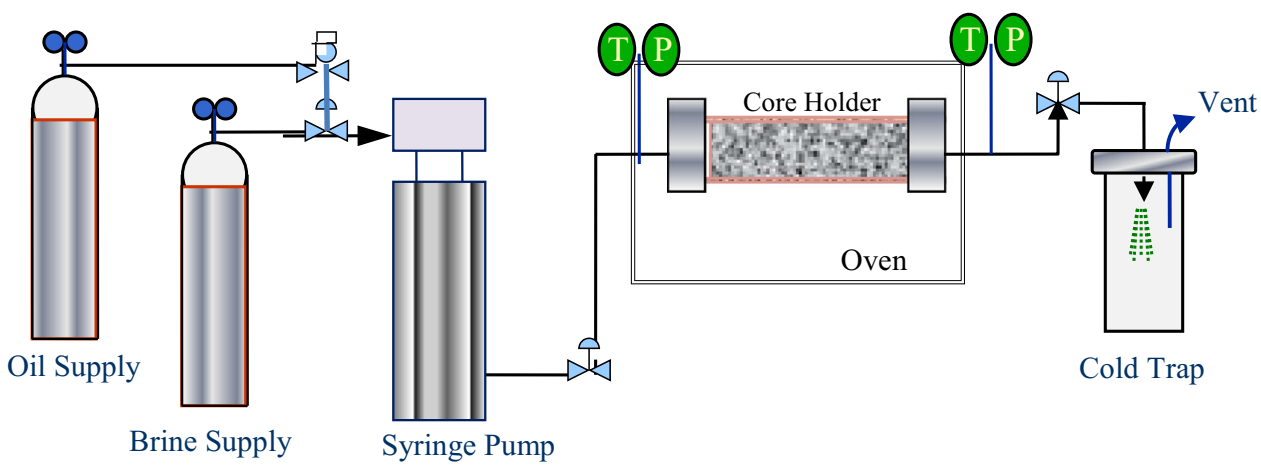

Table 1 Rock properties of actuals samples used

\begin{tabular}{llccccc}
\hline Sample/well \# & $\varnothing_{\text {sh }}$ fraction & $K_{\text {sh }}$ md & $\varnothing_{\text {Z ratio }}$ & RQI $\mu \mathrm{m}$ & $\sqrt{K / \varphi}$ SQRT(md) & SN dimensionless \\
\hline 1-A & 0.228 & 30.42 & 0.295 & 0.363 & 11.55 & 71.25 \\
2-A & 0.321 & 43.56 & 0.473 & 0.366 & 11.65 & 71.87 \\
3-A & 0.264 & 38.56 & 0.359 & 0.379 & 12.09 & 74.57 \\
4-A & 0.096 & 1.83 & 0.244 & 0.401 & 12.76 & 78.75 \\
5-A & 0.187 & 1.90 & 0.095 & 0.367 & 11.70 & 72.16 \\
6-B & 0.216 & 0.70 & 0.157 & 0.279 & 8.87 & 54.73 \\
7-B & 0.136 & 10.71 & 0.082 & 0.489 & 15.58 & 96.13 \\
8-B & 0.155 & 1.14 & 0.070 & 0.131 & 4.188 & 25.84 \\
9-B & 0.283 & 1.04 & 0.395 & 0.236 & 7.529 & 46.45 \\
10-B & 0.175 & 52.10 & 0.212 & 0.542 & 17.25 & 106.46 \\
11-C & 0.213 & 28.20 & 0.271 & 0.361 & 11.51 & 70.99 \\
12-C & 0.323 & 11.80 & 0.477 & 0.190 & 6.04 & 61.22 \\
13-C & 0.197 & 56.34 & 0.245 & 0.531 & 16.91 & 104.34 \\
14-C & 0.274 & 36.34 & 0.377 & 0.362 & 11.52 & 71.06 \\
15-C & 0.246 & 41.45 & 0.326 & 0.408 & 12.98 & 80.09 \\
\hline
\end{tabular}

when the production ceased. The permeability to oil was established at irreducible water saturation $\left(S_{\mathrm{wi}}\right)$ and was used as the base permeability when calculating relative permeability ratio $\left(K_{\mathrm{rw}} / K_{\mathrm{ro}}\right)$. The flood oil displaced and total production were recorded as a function of time. The flow was terminated when zero oil production recovered. Oil-water interfacial tension is measured to be 28.30 dyne/ $\mathrm{cm}$. An example of the brine-oil relative permeability result of sample 13-C is presented in Table 2.

\section{Application and evaluation of reservoir characterization techniques}

The measured experimental data of porosity and permeability, listed in Table 1, and end points of relative permeability, in Table 2, are used to test the suitability of permeability-porosity crossplot and FZI techniques, respectively, for identification of flow units of shaly sandstone reservoirs.

\section{Application of permeability-porosity crossplot technique}

Most wells of this reservoir are often not cored. Therefore, a correlation has to be developed for permeability estimation in uncored sections/wells. A plot of log permeability versus porosity of shaly sandstone is presented in Fig. 2. Porosity-permeability correlation was developed using the petrophysical data, Table 1 . The correlation is in the following form:

$K_{\mathrm{sh}}=74.408 \varnothing_{\mathrm{sh}}+12.594$

The above relationship, Eq. 10, shows a poor correlating coefficient $\left(R^{2}\right)=0.1509$. Equation 10 cannot be used generally throughout the reservoir to predict permeability using porosity data for other facies of the field. The developed permeability correlation have the following disadvantages: (1) They do not have good correlation coefficients $\left(R^{2}\right)=0.15$ for wells $\mathrm{A}, \mathrm{B}$, and $\mathrm{C}$, which make them not representative tools for predicting permeability, and (2) they are not capable of 
Table 2 Brine/oil relative permeability measured for sample 13-C

\begin{tabular}{|c|c|c|c|}
\hline Depth & $6513 \mathrm{ft}$ & Sample \# & $13-\mathrm{C}$ \\
\hline Brine $\mathrm{K}$ & $56.34 \mathrm{md}$ & Porosity & $19.7 \%$ \\
\hline$K_{\mathrm{ro}}^{\mathrm{a}} @ S_{\mathrm{wi}}$ & $53.13 \mathrm{md}$ & $S_{\mathrm{wi}}$ & $44.4 \%$ \\
\hline$K_{\mathrm{rw}}^{\mathrm{a}} @ S_{\mathrm{or}}$ & $11.02 \mathrm{md}$ & $S_{\text {or }}$ & $26.5 \%$ \\
\hline Brine saturation (\% PV) & $K_{\mathrm{ro}}$ & $K_{\mathrm{rw}}$ & $K_{\mathrm{rw}} / K_{\mathrm{ro}}$ \\
\hline 44.3 & 1.0000 & - & - \\
\hline 50.2 & 0.4073 & 0030 & 0.074 \\
\hline 51.5 & 0.3205 & 0.038 & 0.119 \\
\hline 52.9 & 0.2438 & 0.046 & 0.188 \\
\hline 54.9 & 0.1723 & 0.058 & 0.339 \\
\hline 57.1 & 0.1236 & 0.071 & 0.578 \\
\hline 58.8 & 0.0905 & 0.084 & 0.929 \\
\hline 60.7 & 0.0618 & 0.101 & 1.641 \\
\hline 62.7 & 0.0397 & 0.115 & 2.897 \\
\hline 64.8 & 0.0221 & 0.133 & 6.026 \\
\hline 67.4 & 0.0981 & 0.157 & 15.92 \\
\hline 69.6 & 0.0042 & 0.175 & 41.40 \\
\hline 71.1 & 0.0019 & 0.192 & 99.54 \\
\hline 73.5 & - & 0.206 & - \\
\hline
\end{tabular}

${ }^{a}$ Relative $\mathrm{K}_{\mathrm{ro}} @ \mathrm{~S}_{\mathrm{wi}}$

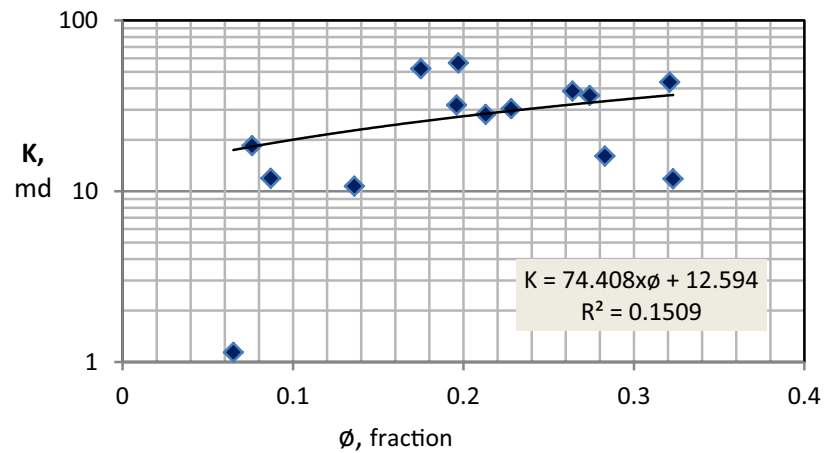

Fig. 2 A plot of log permeability versus porosity

predicting flow units of the reservoir. A graphical plot of permeability versus porosity is depicted in Fig. 2 .

\section{Application of flow zone index (FZI) technique}

The RQI is calculated using data of Table 1 and plotted versus ratio of pore volume to grain volume $(\varphi \mathrm{z})$ on a log$\log$ figure, as shown in Fig. 3. Figure 3 describes a severe scattering degree of data points and unsuitability to define flow units. This indicated that the application of the FZI technique does not provide good identification of reservoir flow units of shaly reservoirs. These unsatisfactory results may be attributed to the heterogeneous nature of shaly sandstone reservoir(s) and/or the non-suitability of the FZI concept for this situation.

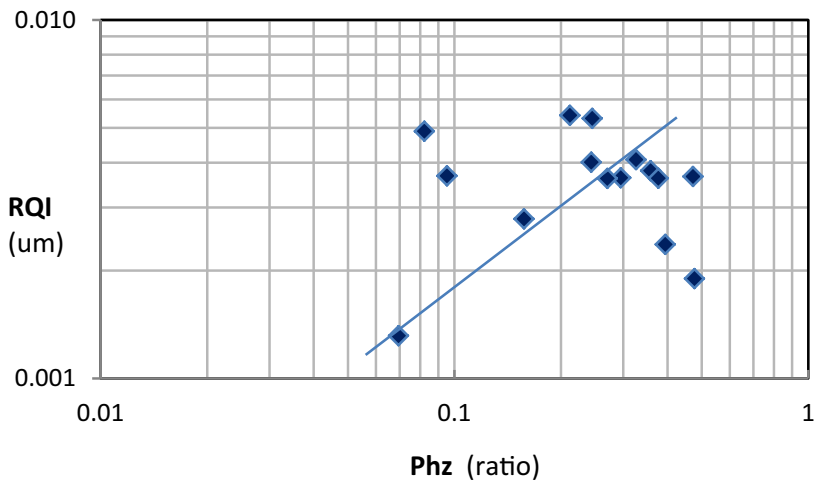

Fig. 3 Log-log plot of RQI versus $\varphi \mathrm{Z}$

According to the above plot, Fig. 3, it is obvious that data from wells $\mathrm{A}, \mathrm{B}$, and $\mathrm{C}$ did not delineate hydraulic flow units. Logarithmic plot of RQI vs. $\varphi \mathrm{z}$ should have unity slope lines in an ideal condition and each line describes a single-hydraulic flow unit.

\section{Microscopic rock characterization using SEM analysis}

Thin slices of $2 \mathrm{~mm}$ each of four core samples (\# 4-A, 5-A, 8-B, and 9-B) were used for microscopic rock characterization.

The analysis of scanning electron microscope (SEM) images indicated that core \# 4-A has detrital clays, minor 
calcite, and traces of Illite clays, as shown in Fig. 4. The SEM image of core \# 4-A indicates the absence of cemented material, existence of minor amount of Illite, and traces of Chloride, as depicted in Fig. 4. The clay type tis identified to be detrital clays and hairy illites replacing detritial clays. The extensions of clays provide good explanation of low porosity and permeability of this sample.

The SEM of core \# 5-A is presented in Fig. 5. Figure 5 confirms rounded gray quartz grains with microfine grains in between. The pore-throat radius shows its maximum at 0.15 microns. These two conditions of micropores and fine grains cause low rock permeability of this sample. This may be explained by fine migration through the pore passages leading to blocking the pores and reducing the permeability. It is important to be reported that traces of tiny fines were observed in the effluent stream. This might be due to damage in the clay structure due to change in the interfaces through the rock.

The SEM image of core sample \# 8-B presented in Fig. 6 identifies the type of clay as hairy Illites. Figure 7 of core sample \# 9-B shows detrital clays filling quartz grains and existence of some alterations at few areas with illite.

\section{Development and application of shale number (SN) technique}

A new concept called shale number (SN) is developed and detailed steps of derivation using mathematical technique of dimensional analysis is presented in "Appendix" as Eq. 21, and given below by Eq. 11 .

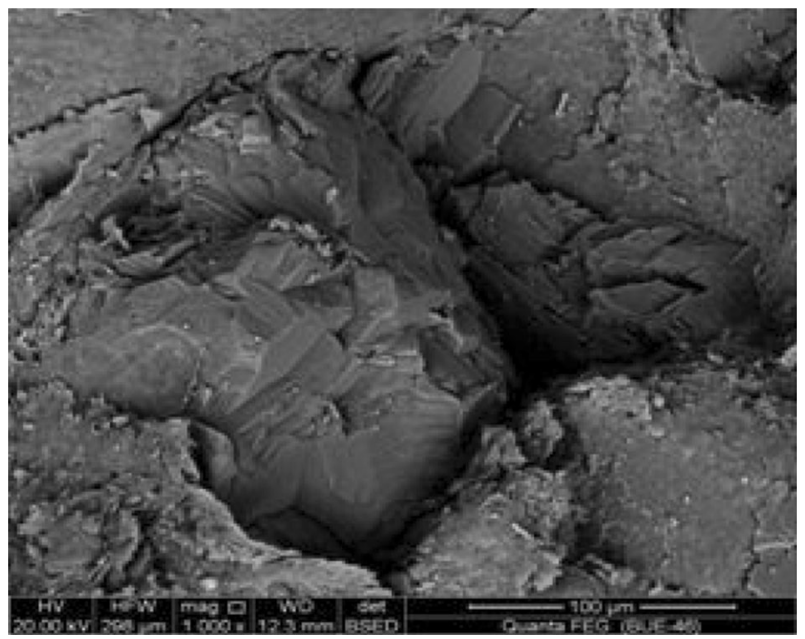

Fig. 4 SEM image $(\times 100)$ - pores filling and grains coating by detrital clays and hairy illites causing low porosity (Core 4-A)

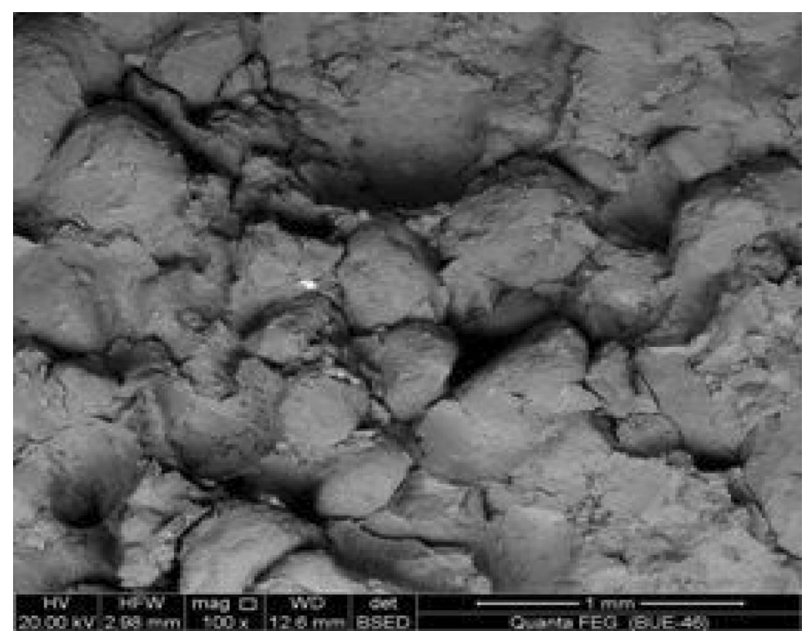

Fig. 5 SEM image $(\times 100)$ - big rounded gray quartz grains with clay between grain (Core $5-\mathrm{A})$

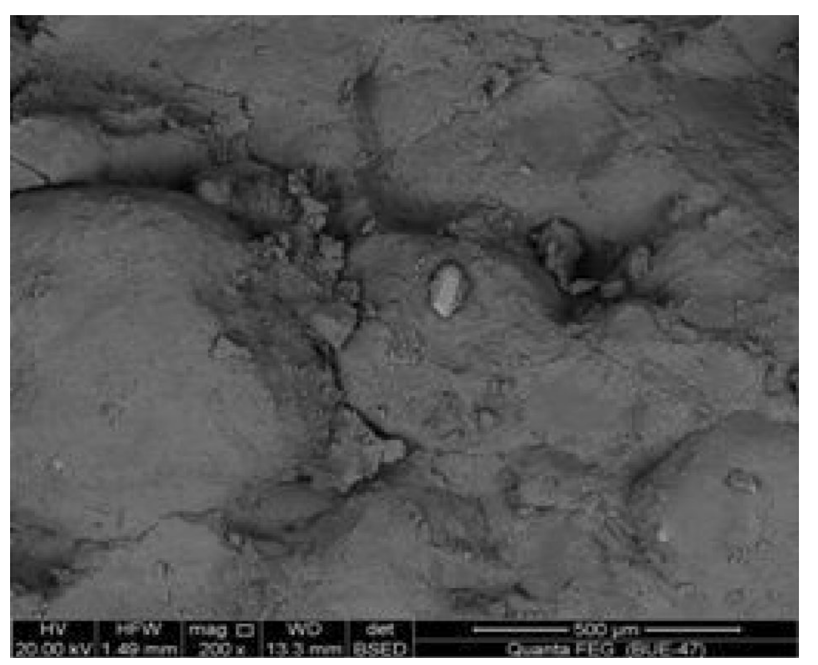

Fig. 6 SEM image $(\times 500)$ - presence of hairy illites filling pore throats between sand grains (Core \# 8-B)

$\mathrm{SN}=\frac{\rho_{\mathrm{o}} \sigma_{\mathrm{ow}}}{\mu_{\mathrm{o}}^{2}}\left(\frac{K_{\mathrm{o}-\mathrm{sh}}}{K_{\mathrm{w}-\mathrm{sh}}}\right)_{\mathrm{EP}} \sqrt{\frac{K_{\mathrm{sh}}}{\varphi_{\mathrm{sh}}}}$

where $\mathrm{SN}$ is shale number (dimensionless), $\sigma_{\mathrm{o}-\mathrm{w}}$ is oilwater interfacial tension $($ dyne $/ \mathrm{cm}), \mu_{\mathrm{o}}$ is oil viscosity (cp), $\rho_{o}$ is oil density $\left(\mathrm{gm} / \mathrm{cm}^{3}\right), \mathrm{k}_{\mathrm{ro}}$ and $\mathrm{k}_{\mathrm{rw}}$ are end-point oil and water relative permeability, respectively, $\varphi_{\mathrm{sh}}$ is shaly sandstone porosity (fraction), and $\mathrm{K}_{\mathrm{sh}}$ is shaly sandstone permeability (md). The shale number $(\mathrm{SN})$ is calculated and plotted versus reservoir quality $\sqrt{K / \varphi}$ yielding three well-defined flow units, as shown in Fig. 8.

Inspection of Fig. 8 shows that the geologically defined facies B consists of three distinct hydraulic flow units. The identified flow units pass through wells $\mathrm{A}, \mathrm{B}$ and $\mathrm{C}$ unless there is a geological barrier. This result is very interesting and means that the shale number technique is capable to 


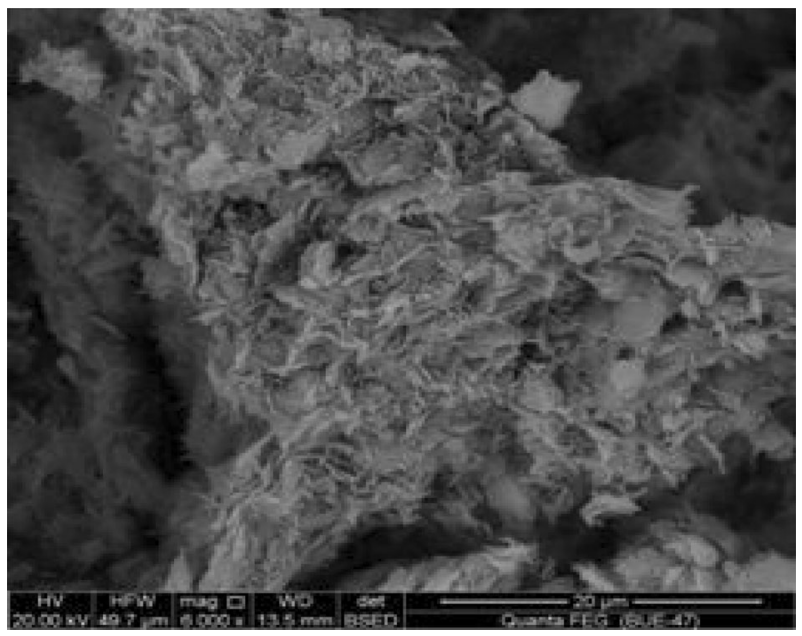

Fig. 7 SEM image (X 200)—detrital clays filling quartz grains and some alterations at few areas with Illite (Core \# 9-B)

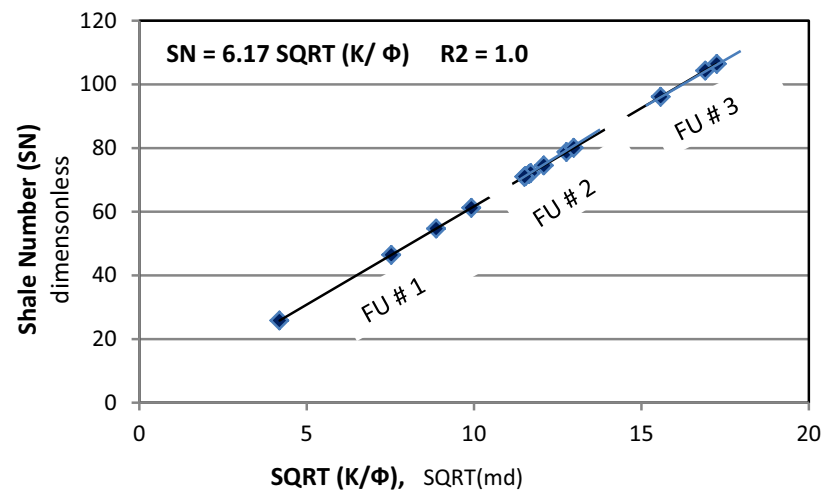

Fig. 8 Cartesian plot of shale number (SN) versus reservoir quality

produce a more refined reservoir description over the description provided using the porosity-permeability crossplot and FZI, as obtained in this study and presentedabove in Figs. 2 and 3, respectively. The sole reason for this more refined reservoir description is that the shale number $(\mathrm{SN})$ considers almost all the important variables of the reservoir such as rock properties (porosity and permeability), contained fluid properties (viscosity and density of oil), and oil-rock petrophysical properties (relative permeability of oil and water, and oil-water interfacial tension).

It is important to emphasize that the application of the RQI concept requires a log-log plot, which usually accumulates data points and reduces accuracy to minimize scattering degree. This RQI log-log plot is based on obtaining a straight line characterizing single flow unit, but the final result still shows high scattering degree of data points and incapability to delineate flow units for shaly sandstone reservoir under investigation, Fig. 3. On the other side, the newly developed shale number $(\mathrm{SN})$ uses a
Cartesian plot, which is more accurate for variation of reservoir properties. The SN plot provides the minimum scattering degree. The SN technique also has another advantage of plotting more rock/fluid variables involved in the SN versus dual parameter of permeability and porosity $(\sqrt{K / \varphi})$ and not versus ratio of pore volume to grain volume $(\varphi \mathrm{z})$ as for FZI technique.

A new equation correlating shale number and reservoir quality is developed and given below:

$\mathrm{SN}=6.17\left(\sqrt{\frac{K_{\mathrm{sh}}}{\varphi_{\mathrm{sh}}}}\right)$

The above equation, Eq. 12, indicates a very good correlating coefficient $R^{2}=1.0$ and has a unique characteristic of a straight line passing through the origin. This equation also can be used to predict the shale number using porosity and permeability of shaly reservoirs. This equation represents a very valuable tool to achieve the minimum cost by calculating shale number without need for other parameters involved in Eq. 11 above.

Rearranging Eq. (11) and taking the logarithm on both sides of the resulting equation yields the following equation:

$\log (\mathrm{SN})=1.0 \log \left(\sqrt{\frac{K_{\mathrm{sh}}}{\varphi_{\mathrm{sh}}}}\right)+\log \left(\frac{\rho_{\mathrm{o}} \sigma_{\mathrm{ow}}}{M \mu_{\mathrm{o}}}\right)$

The developed model in Eq. 13 above reveals that a $\log -\log$ plot of SN versus reservoir quality should develop a unit slope line describing a flow unit with unique slope of unity.

\section{Conclusions}

This study used SEM technology and mathematical dimensional analysis to develop a new practical technique capable to identify clay type and flow units in shaly sandstone reservoirs. The newly developed approach is general, robust, and considers many rock and fluid properties. The conclusions of this study are summarized as follows;

1. Scanning electron microscope (SEM) has been used successfully for microscopic reservoir characterization. The SEM images are capable to identify clay type as detrital clays and hairy illites plus clay distribution as filling micropores and coating grains of shaly sandstone formations.

2. Permeability-porosity crossplot and flow zone index techniques have shown poor performance and incapability to identify flow units in shaly sandstone reservoirs. 
3. A new concept/technique has been developed to identify flow units constituting shaly sandstone reservoirs. This technique is called shale number (SN) and considers rock and fluid properties, petrophysical properties and dynamic flow conditions.

4. A mathematical model is developed using dimensional analysis and has been validated using actual shaly sandstone rock and fluid samples.

5. The results indicated better identification of flow units using the shale number model in comparison to other rock characterization techniques.

Acknowledgements This work is conducted as a part of a funded research project supported by the American University in Cairo, AUC, under the contract agreement \# SE-PENG-FY 17-RG (2)-2016. The author is grateful to the AUC management for funding this project and encouragement for publication. The author would also like to thank the operating company for continuous support and provision of required fluid and rock samples.

Open Access This article is distributed under the terms of the Creative Commons Attribution 4.0 International License (http:// creativecommons.org/licenses/by/4.0/), which permits unrestricted use, distribution, and reproduction in any medium, provided you give appropriate credit to the original author(s) and the source, provide a link to the Creative Commons license, and indicate if changes were made.

\section{Appendix: development the concept of shale number (SN)}

The shale number (SN) is a new concept combining various rock and fluid properties plus dynamic flow condition affecting description of shaly sandstone reservoirs. These properties include rock properties of porosity and permeability, oil viscosity, oil-water interfacial tension, and dynamic properties of oil and water relative permeabilities. Shale number is a function of the variables listed in Eq. 14:

Characterization shaly number (SN)

$$
=f\left(K_{\mathrm{sh}}, \varphi_{\mathrm{sh}}, V_{\mathrm{o}}, V_{\mathrm{w}}, \mu_{\mathrm{o}}, \mu_{\mathrm{w}}, \sigma_{\mathrm{ow}}, \rho_{\mathrm{o}}, . D_{\mathrm{p}}\right)
$$

Dimensions of variables listed above and involved in the shale number $(\mathrm{SN})$ are listed:

$$
\begin{array}{lll}
K_{\mathrm{sh}}=\left[L^{2}\right] & V_{\mathrm{o}}=[L / T] & V_{\mathrm{w}}=[L / T] \\
D_{\mathrm{p}}=[L] & \mu_{\mathrm{o}}=[M / \mathrm{LT}] & \mu_{\mathrm{w}}=[M / \mathrm{LT}] \\
\sigma_{\mathrm{ow}}=\left[M / T^{2}\right] & D_{\mathrm{p}}=[L] & \Phi_{\mathrm{sh}}=\left[L^{3} / L^{3}\right]=\text { dimensionless } \\
\rho_{\mathrm{o}}=\left[M / L^{3}\right] & &
\end{array}
$$

Applying dimensional analysis technique yields the following dimensionless groups:

$\pi_{1}=\frac{\rho_{\mathrm{o}} V_{\mathrm{o}} D_{\mathrm{p}}}{\mu_{\mathrm{o}}}$

$$
\begin{aligned}
& \pi_{2}=\frac{\sigma_{\mathrm{ow}}}{V_{\mathrm{w}} \mu_{\mathrm{w}}} \\
& \pi_{3}=\frac{\sqrt{K_{\mathrm{sh}} / \varphi_{\mathrm{sh}}}}{D_{\mathrm{P}}}=\frac{\mathrm{RQI}_{\mathrm{sh}}}{D_{\mathrm{P}}}
\end{aligned}
$$

Multiplication of the three-above dimensionless groups, Eqs. (15-17), provides the following equation;

$\mathrm{SN}=\frac{\rho_{\mathrm{o}} \sigma_{\mathrm{ow}}}{\mu_{\mathrm{o}} \mu_{\mathrm{w}}}\left(\frac{V_{\mathrm{o}}}{V_{\mathrm{w}}}\right) \sqrt{\frac{K_{\mathrm{sh}}}{\varphi_{\mathrm{sh}}}}$

Using Darcy's law for oil and water flow, velocities can be expressed as follows:

$V_{\mathrm{o}}=\frac{2 \pi K_{\mathrm{o}} h\left(P_{\mathrm{e}}-P_{\mathrm{wf}}\right)}{\mu_{\mathrm{o}} \ln \left(r_{\mathrm{e}} / r_{\mathrm{w}}\right)}$ and $V_{\mathrm{w}}=\frac{2 \pi K_{\mathrm{w}} h\left(P_{\mathrm{e}}-P_{\mathrm{wf}}\right)}{\mu_{\mathrm{w}} \ln \left(r_{\mathrm{e}} / r_{\mathrm{w}}\right)}$

Dividing oil velocity $\left(\mathrm{V}_{\mathrm{o}}\right)$ by water velocity $\left(\mathrm{V}_{\mathrm{w}}\right)$ from Eq. (19) yields;

$\frac{V_{\mathrm{o}}}{V_{\mathrm{w}}}=\left(\frac{K_{\mathrm{o}}}{K_{\mathrm{w}}}\right)\left(\frac{\mu_{\mathrm{w}}}{\mu_{\mathrm{o}}}\right)=\left(\frac{K K_{\mathrm{ro}}}{K K_{\mathrm{rw}}}\right)\left(\frac{\mu_{\mathrm{w}}}{\mu_{\mathrm{o}}}\right)=\left(\frac{K_{\mathrm{ro}}}{K_{\mathrm{rw}}}\right)\left(\frac{\mu_{\mathrm{w}}}{\mu_{\mathrm{o}}}\right)$

Substitution of Eq. (20) into Eq. (18) yields the shale number (SN) below:

$\mathrm{SN}=\frac{\rho_{\mathrm{o}} \sigma_{\mathrm{ow}}}{\mu_{\mathrm{o}}^{2}}\left(\frac{K_{\mathrm{o}-\mathrm{sh}}}{K_{\mathrm{w}-\mathrm{sh}}}\right)_{\mathrm{EP}} \sqrt{\frac{K_{\mathrm{sh}}}{\varphi_{\mathrm{sh}}}}$

Rearranging Eq. (21) and taking the logarithm on both sides of the resulting equation results in the following equation:

$\log (\mathrm{SN})=1.0 \log \left(\sqrt{\frac{K_{\mathrm{sh}}}{\varphi_{\mathrm{sh}}}}\right)+\log \left(\frac{\rho_{\mathrm{o}} \sigma_{\mathrm{ow}}}{M \mu_{\mathrm{o}}}\right)$

Assuming water viscosity is equal unity, then Eq. (21) is written as a function of water-oil mobility ratio (M), as below;

$\mathrm{SN}=\left(\frac{\rho_{\mathrm{o}} \sigma_{\mathrm{ow}}}{M \mu_{\mathrm{o}}}\right) \sqrt{\frac{K_{\mathrm{sh}}}{\varphi_{\mathrm{sh}}}}$

where $\mathrm{M}$ is the water-oil mobility ratio, which is defined by Lake (2010) as below:

$M=\left(\frac{K_{\mathrm{w}-\mathrm{sh}}}{\mu_{\mathrm{w}}}\right)\left(\frac{\mu_{\mathrm{o}}}{K_{\mathrm{o}-\mathrm{sh}}}\right)$

where $K_{\mathrm{rw}}$ and $K_{\mathrm{ro}}$ are the water and oil relative permeability, respectively. Craig (1971) indicated that the end points of oil and water relative permeability are considered as a good indication for reservoir wettability. 


\section{References}

Ahmed T (2001) Reservoir engineering handbook, 3rd edn. Gulf Publishing Company (GPC), Houston

Amaefule JO, Atubay M, Tiab D, Kersey DG, Keelan D (1993) Enhanced reservoir description: using core and $\log$ data to identify hydraulic (flow) units and predict permeability in uncored intervals/wells, SPE 26436, presented at the 66th annual technical conference and exhibition of the SPE, Houston, Texas 3-6 October, pp 205-217

Coates GR, Dumanoir JL (1973) A new approach to improved log derived permeability. In: 14th Annual logging symposium. Transactions of the Society of Professional Well Log Analysts Lafayette, LA, USA, May 6-9

Craig FF Jr (1971) The reservoir engineering aspects of waterflooding, vol 3., Monograph Series, SPE, USASociety of Petroleum Engineers, Richardson

Duval B (2002) Sedimentary geology: sedimentary basins, depositional enviornments and petroleum formation. Editions Technip, Paris

Ebanks WJ (1987) Flow unit concept-integrated approach to reservoir description for engineering projects, AAPG Data Pages. Inc., Meeting. Abstract, vol 1, no 5, pp 521-522

Haldorsen HH, Damsleth E (1993) Challenges in reservoir characterization. Geohorizons 77(4):541-551

Jennings JW, Lucia FJ (2001) Predicting permeability from well logs in carbonates with a link to geology for interwell permeability mapping, SPE paper 71336. In: The SPE annual technical conference and exhibition, New Orleans, 30 September-3 October, pp 1-16

Jongkittinarukorn K, Tiab D (1997) Identification of flow units in shaly sand reservoirs. J Pet Sci Eng 17:237-246

Lake L (2010) Enhanced oil recovery. Society of Petroleum Engineers publication, Richardson

Lee SH, Datta-Gupta A (1999) Electrofacies characterization and permeability predictions in carbonate reservoirs: role of multivariate analysis and non-parametric regression, paper SPE 56658. In: The 1999 SPE annual technical conference and exhibition held in Houston, Texas, 3-6 October

Leverette MC (1941) Capillary behavior in porous solids, SPE941152-G. Trans AIME 142:152-169

Moore DE, Morrow CA, Byerlee JD (1982) Use of swelling clays to reduce permeability and its potential application to nuclear waste repository sealing. Geophys Res Lett 9:1009-1012
Phillips C (1996) Enhanced thermal recovery and reservoir characterization. In: AAPG Pacific section, old oil fields and new life: a visit to the giants of the Los Angeles basin, Tidelands Oil Production Company, California, pp 65-82

Pittman ED (1992) Relationship of porosity and permeability to various parameters derived from mercury injection-capillary pressure curve for sandstone. AAPG Bull 76(2):191-198

Revil K, Cathles LM (1999) Permeability of shaly sands. Water Resour Res 35:651-662

Shedid SA (2001) Multi-purpose reservoir characterization model, SPE 68105. In: The 12th SPE middle east oil show \& conference (MEOS), Manama, Bahrain, March 17-20

Shedid SA, Almehaideb RA (2003) Enhanced reservoir description of heterogeneous carbonate reservoirs. J Can Pet Technol (JCPT) 42(7):23-28

Shedid Elgaghah SA, Tiab D, Osisanya S (2001a) A new approach for obtaining $\mathrm{j}$-function in clean and shaly reservoirs using in situ measurements. J Can Pet Technol 40:30-37

Shedid Elgaghah SA, Tiab D, Osisanya SO (2001b) Influence of stress on the characteristics of flow units in shaly formations. J Can Pet Technol 31-40

Shedid SA, Tiab D, Osisanya S (1998a) Improved reservoir description of Shaly Sands using conventional well-log derived data for flow units identification. In: SPE 39803, presented at the Permian Basin Oil and Gas Recovery Conference, Midland, Texas, USA, March 25-27

Shedid SA, Tiab D, Osisanyia S (1998b) Enhanced reservoir characterization using NMR core data and well-log derived data. In: SPE 39810, presented at the Permian Basin Oil and Gas Recovery Conference, Midland, Texas, USA, March 25-27

Shedid SA, Tiab D, Osisanya S (1998c) In-situ permeability-porosity relationship in clean formations, The Canadian Petroleum Society, Paper 98-35, the 49th annual technical meeting of the petroleum society in Calgary, Alberta, Canada, June 8-10

Tiab D, Donaldson E (2004) Petrophysics-theory and practice of measuring reservoir rock and fluid transport properties. Gulf Professional Publishing, Oxford

Toby D (2005) Well logging and formation evaluation. Elsevier, San Francisco

Winland HD (1972) Oil accumulation in response to poe size changes, weyburn field, Saskatchewan, Amoco Production Research, paper no F72-G 25 